\title{
TIPOLOGIAS DO CARSTE E CLASSIFICAÇÕES DE DOLINAS: UMA REVISÃO
}

\author{
Cristiano Fernandes Ferreira \\ Universidade de Brasília - UnB \\ Programa de Pós-Graduação em Geografia \\ cristiano.ferreira@icmbio.gov.br \\ Rogério Elias Soares Uagoda \\ Universidade de Brasília - UnB \\ Programa de Pós-Graduação em Geografia \\ rogeriouagoda@unb.br
}

\begin{abstract}
RESUMO
O carste apresenta processos característicos e complexos ligados à dissolução que podem resultar em feições típicas destes ambientes, como as dolinas. A ocorrência de ambientes cársticos diferenciados motivou diversas propostas tipológicas ou de classificação dessas paisagens. O presente trabalho revisa as principais formas de se categorizar o carste ao longo do tempo no mundo e algumas propostas que tiveram maior aplicação no Brasil. A evolução da discussão sobre o tema resultou cada vez mais no entendimento dos processos espeleogenéticos que ocorrem preferencialmente em subsuperfície. Esses mecanismos subjacentes são os responsáveis principais pela origem e desenvolvimento das depressões cársticas, como as dolinas. Devido à dificuldade de se classificar estas feições e falta de convergência na denominação dos tipos de dolina, buscou-se reunir as diversas propostas que foram sendo elaboradas na literatura internacional. A partir da revisão destas propostas realizou-se uma síntese de classificação genéticas de dolinas para uniformizar a aplicação em trabalhos futuros.
\end{abstract}

Palavras-chave: Carste. Dolina. Depressão fechada.

\section{KARST TYPOLOGIES AND DOLINES CLASSIFICATIONS: A REVIEW}

\begin{abstract}
The karst presents characteristic and complex processes related to the dissolution that can result in features typical of these environments, like the dolines. The occurrence of different karst environments motivated several typological proposals or classification of these landscapes. This paper reviews the main ways to categorize karst over time in the world and some proposals that have been most widely applied in Brazil. The evolution of the discussion on the subject has resulted more and more in the understanding of the speleogenetic processes that occur preferentially in subsurface. These underlying mechanisms are primarily responsible for the origin and development of karst depressions, such as dolines. Due to the difficulty of classifying these features and lack of convergence in the denomination of doline types, it was sought to bring together the various proposals that have been elaborated in the international literature. From the review of these proposals a synthesis of genetic classification of dolines was made to standardize the application in future works.
\end{abstract}

Keywords: Karst. Sinkholes. Closed derpression.

\section{INTRODUÇÃO - O QUE É CARSTE?}

O carste pode ser considerado um tipo de terreno com formas e sistemas de drenagens diferenciados pela combinação de alta solubilidade da rocha e porosidade secundária bem desenvolvida, através de alargamento de fraturas e descontinuidades (FORD e WILLIAMS, 2007). Esta solubilidade é encontrada preferencialmente em rochas carbonáticas, como calcários, dolomitos e mármores, que são atacados por água naturalmente acidulada, representada principalmente através da seguinte reação reversível: $\mathrm{CaCO}^{3}+\mathrm{H}^{2} \mathrm{O}+\mathrm{CO}^{2}=\mathrm{Ca}\left(\mathrm{HCO}^{3}\right)^{2}$. O intemperismo químico é o processo dominante 
se comparado ao transporte mecânico, resultando num conjunto único de paisagens (JONES e WHITE, 2012). Tais terrenos são caracterizados pela ocorrência de depressões fechadas (dolinas), captura de drenagens superficiais para sistemas subterrâneos e ocorrência de cavernas (GILLIESON, 1996; FORD e WILLIAMS, 2007). A dissolução pela água, através dos interstícios da rocha, é o processo chave e mesmo que não seja predominante, é o mecanismo inicial que permite outros ocorrerem, como erosão mecânica e colapsos (FORD, 2004; PALMER, 2007). O carste pode ser entendido como um conjunto de características morfológicas e hidrológicas, superficiais e subterrâneas, relacionadas ao mecanismo dominante sobre elas, a dissolução de rochas solúveis, notadamente carbonatos e evaporitos, dando origem a "feições endêmicas" deste tipo de ambiente (GUTIERREZ et al., 2014). É importante ressaltar que nos trópicos úmidos os processos de carstificação são ainda mais pronunciados, seja pela alta disponibilidade de ácidos carbônicos oriundos da interação ar, solo e vegetação, seja pela maior quantidade de água disponível (WALTHAM et al., 2005).

Dada a especificidade processual e o desenvolvimento de formas tão peculiares nestes ambientes, o objetivo principal deste trabalho é revisitar as principais contribuições relacionadas ao carste, focando inicialmente nas formas de classificação destas paisagens. Numa segunda parte e considerando a grande importância das dolinas como uma das principais e mais típicas expressões morfológicas do carste, além de seu relevante papel hidrológico e ambiental, será tratada a questão das formas de seu desenvolvimento genético e morfológico assim como as classificações destas feições. Ressalta-se que são poucas as revisões sobre geomorfologia cárstica no Brasil, especialmente após meados da década de 1990 e início dos anos 2000, embora discussões e avanços sobre o assunto tenham tido continuidade em nível mundial. Além disso identificou-se uma certa variedade de nomes e processos aplicados ao conceito de dolina, o que motivou a realização desta revisão sobre o tema, em busca de maior uniformização.

\section{CLASSIFICAÇÕES DO CARSTE E ASPECTOS MORFOGENÉTICOS}

Uma das primeiras classificações foi proposta pelo próprio Jovan Cvijić, considerado o pai da geomorfologia e hidrologia cárstica, em seus trabalhos entre 1893 e 1925, que estabeleceram a diferenciação entre o "holocarste" e o "merocarste" (FORD e WILLIAMS, 2007; FORD, 2007). O holocarste, seria constituído pelo carste completo, em espessas camadas de calcário puro, sem a interferência de outras rochas menos solúveis, onde se desenvolve toda a gama de feições cársticas. Já o merocarste, seria incompleto, constituído pela intercalação de outras rochas menos ou totalmente insolúveis que levam ao desenvolvimento misto da paisagem entre componentes subterrâneo e fluvial. Estes termos caíram naturalmente em desuso, visto que o carste autêntico previsto por Cvijić na verdade era a exceção no âmbito mundial, muito além dos Alpes Dináricos carbonáticos onde o autor se inspirou. Conforme Ford (2007) o termo merocarste foi alternado para outra classificação atualmente muito usada para diferenciar áreas cársticas, o fluviocarste. 0 fluviocarste se desenvolve tanto pela ação da dissolução como por forças mecânicas de remoção, transporte e deposição de materiais, criando paisagens fluviais ora superficiais, ora subterrâneas, com a instalação de vales cegos e janelas cársticas, que podem ser consideradas um tipo de dolina de colapso. Jennings (1985) relata que foi Roglic (1960) quem propôs o termo para diferenciar as áreas que apesar de ocorrerem em calcários puros, por uma série de razões, a ação mecânica da água na superfície impede a expressão completa da dissolução.

Uma das formas mais utilizadas no Brasil para classificação do carste parte da divisão entre exocarste e endocarste, difundida na Europa, através principalmente da publicação de Bögli (1980). Segundo o mesmo, o exocarste pode ser definido como o conjunto de formas superficiais geradas a partir da corrosão em rochas solúveis pela água de chuva, compreendendo desde lapiás, pequenas depressões fechadas como dolinas, uvalas, cenotes e cockpits, além das planícies de corrosão, vales cársticos, vales secos e as grandes depressões, os poljés. Já o endocarste, segundo Bögli, é caracterizado pelos processos cársticos que ocorrem no subterrâneo, com a gradual captura da água superficial pela rede de drenagem formada através de juntas e planos de acamamento da rocha, que aos poucos vão se alargando até formarem cavernas. Essa classificação, por ser bem didática, foi posteriormente muito utilizada no meio acadêmico brasileiro, sendo adotada por autores e publicações de grande difusão, como Bigarela et al. (1994) e Kohler (1995). Posteriormente Piló (1998; 2000) reforça essa classificação adicionando, ainda, o conceito de epicarste, entendido como um domínio de intersecção entre o exo e endocarste. 
Pouco depois de Bögli (1980), publicações em língua inglesa como as de White (1988) e Jennings (1985) se utilizam dos termos "formas superficiais e subterrâneas do carste", prevalecendo na literatura internacional em contraposição aos termos "exo e endocarste". A partir de então contribuições são feitas no sentido de valorizar mais os aspectos genéticos, especialmente hidrológicos, nas classificações do carste em detrimento de apenas aspectos descritivos, relacionados as formas visíveis decorrentes dos processos de dissolução no subterrâneo.

Neste sentido, num dos primeiros trabalhos de síntese de Palmer (1984) o autor propõe outra classificação para o que ele chama de ambientes genéticos do carste, destacando: as formas superficiais em rochas aflorantes (lapiás, cânions); as feições de carste de subsolo que é condicionado pelo fluxo em meio poroso; as formas características de zona vadosa em que o fluxo é livre e gravitacional; feições de zona freática, com fluxos confinados e; as formas criadas pela alternância entre os dois últimos. Nesta publicação o autor reforça a importância dos aspectos hidrológicos no carste, identificando as interrelações entre as formas de recarga hídrica (autogêngica, alogênica, difusa) e sua repercussão em formas superficiais e subterrâneas, como no padrão planimétrico de cavernas (dendrítico ou em rede, por exemplo). Também define as zonas hidrológicas vadosas, freáticas e de variação do nível do lençol, defendendo a evolução simultânea de tais setores com possíveis repercussões em superfície através de colapsos de rocha e solo.

Uma outra tipologia processual do carste foi identificada para áreas tropicais úmidas inicialmente na Nova Guiné, por Williams (1972), e posteriormente aplicada em outras partes do mundo, inclusive no Brasil. Neste trabalho o autor conseguiu detectar alguns padrões morfológicos superficiais nos oito distritos analisados, que diferiam entre a ocorrência de pináculos de cumes acentuados, torres com encostas escarpadas, cones de perfil mais arredondados e sequência de dolinas tipo cockpits. A partir de análises mais acuradas, com apoio de interpretações morfométricas, foi observado que estas feições se organizavam e desenvolviam como fruto da ação morfogenética de depressões intramontanas, que capturavam o escoamento hídrico superficial. Se estas depressões fechadas evoluem e escavam completamente as paisagens, se justapondo umas às outras lateralmente, podem formar um mosaico de depressões de contornos topográficos (pentagonais ou hexagonais) sob a forma de uma rede celular denominada poligonal. O crescimento das depressões poligonais é limitado pela permeabilidade da rocha e a manutenção das bordas se dá pela competição entre depressões adjacentes. Desta forma, uma vez estabilizada uma depressão poligonal, ela tende a manter seu formato, desde que não haja mudanças ambientais significativas. Apesar disso, a drenagem interna para os sumidouros (pode haver mais de um), de natureza efêmera e centrípeta, pode sofrer aumento da assimetria com o crescimento da depressão. No carste poligonal, as depressões representam o centro dinâmico do sistema, condicionando a forma das feições superficiais residuais (torres, cones, pináculos), que primeiramente podem chamar mais atenção. De acordo com Ford e Williams (2007), o carste poligonal é uma das formas de drenagem natural mais eficientes que existem.

Essa classificação de carste poligonal influenciou um importante trabalho realizado no Brasil por Karmann (1994), na região cárstica do Vale do Rio Ribeira-SP. Neste trabalho o autor realizou uma classificação transicional das áreas estudadas entre zona fluvial (sobre os carbonatos), zona de contato (capturas de águas alogênicas), zona fluviocarstica, zona de transição e por fim, zona de carste poligonal (águas autogênicas). Desta forma ficou demonstrado o desmembramento da rede de drenagem superficial em bacias poligonais fechadas, o que é convergente com a ideia de uma fase fluvial e superficial anterior à carstificação, postulada por diversos autores desde 1900, conforme Ford e Williams (2007).

Utilizando também de critérios genéticos, funcionais e evolutivos para distinguir os diferentes tipos de carste, Klimchouk e Ford (2000), apresentam uma classificação adaptada do trabalho de Klimchouk (1996), baseada na condição de cobertura, profundidade da carstificação e remoção de materiais, dentre outros aspectos (Figura 1). O carste singenético se refere a feições criadas por dissolução durante a deposição do mineral (calcita ou gipsita) em eventos de exposição subaérea (regressão marinha). O carste intraestratal pode ser dividido em profundo, subjacente e entrincheirado. Carste profundo não é evidente em superfície, com rochas solúveis não expostas, mas em processo de carstificação por águas acidificadas ou termais - equivalente ou muito próximo ao conceito posteriormente consolidado de carste hipogênico. O carste subjacente ocorre onde as rochas solúveis são cortadas pela erosão em pontos de menor espessamento da camada superior insolúvel, causando alguns colapsos e surgências pontuais. O carste entrincheirado ocorre quando toda a 
massa de rocha solúvel é recortada por vales, mas permanecem capas de rochas insolúveis nos interflúvios. Numa transição de carste intraestratal para carste exposto figura um tipo resultante da evolução dos três subtipos descritos anteriormente, o carste desnudo, que se forma quando toda a massa de rocha sobrejacente antecedente foi removida, o que implica que necessariamente já foi em algum momento capeado por outra rocha insolúvel.

Já quanto aos subtipos de carste exposto, observa-se uma sequência de carste aberto para carste coberto, que pode ser profundamente enterrado e ambos posteriormente formarem o carste exumado. Neste sentido carste aberto corresponde aquele que nunca foi coberto ou, se foi, a remoção da cobertura se deu antes de qualquer carstificação e, portanto, não há heranças morfológicas de estágios cobertos. Carste coberto é caracterizado pela cobertura de uma significativa camada de sedimentos inconsolidados acumulados concomitantemente durante a evolução cárstica, seja por solos de descalcificação (autóctone) ou por materiais de fora do carste (alóctone). Carste enterrado ocorre quando as rochas já anteriormente carstificadas são completamente soterradas por outra rocha, normalmente por transgressão marinha, interrompendo os processos de dissolução. Neste caso observa-se uma forte relação e ambiguidade com o conceito de paleocarste e fossilização. Por fim, o carste exumado é um tipo derivado dos dois anteriores cujos sedimentos que os recobriam posteriormente voltaram a ser removidos.

Figura 1 - Tipologias do carste segundo Klimchouk (2015). Esta figura foi atualizada desde Klimchouk e Ford (2000), com a adição da separação entre carste epigênico e hipogênico.

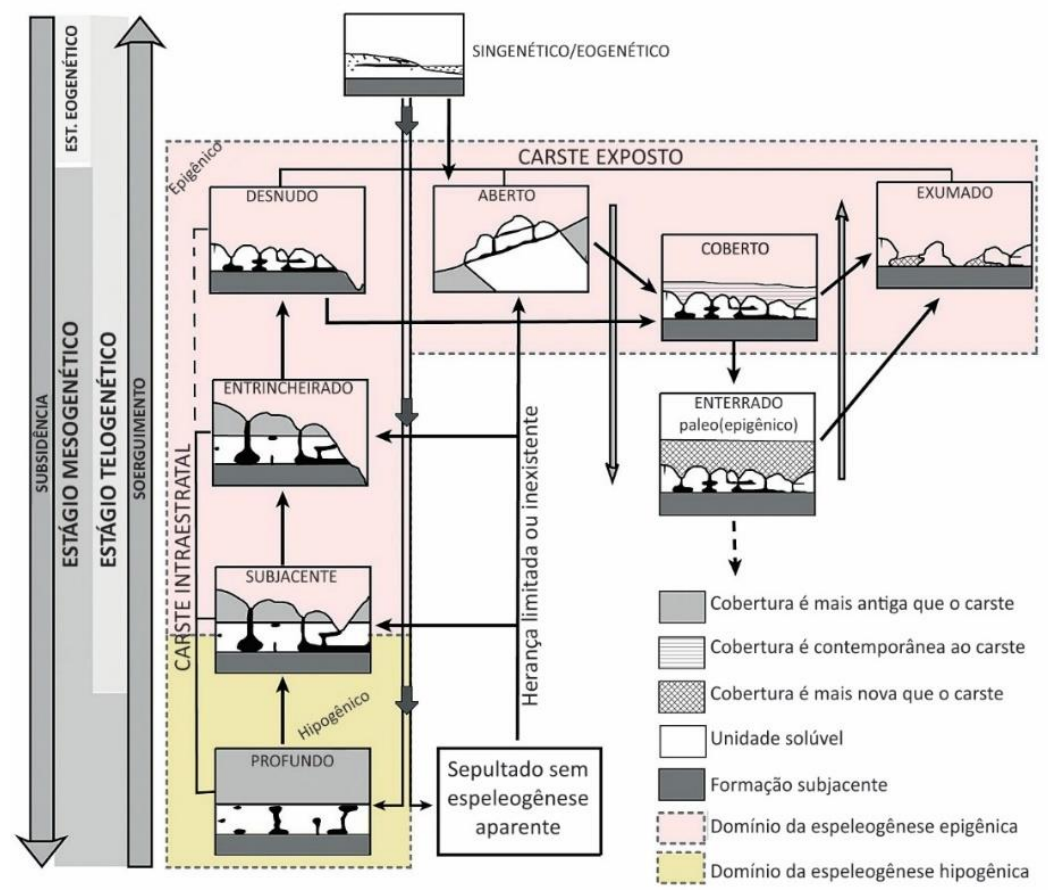

Fonte - adaptado de KLIMCHOUK (2015).

Uma classificação simples, mas bastante funcional é proposta por Ford e Williams em vários trabalhos (mas originalmente em FORD e WILLIAMS, 1989), e estabelece a diferenciação básica entre formas de recarga hídrica (input landforms) e formas de descarga/residuais (outputs e residual landforms). Na primeira categoria entrariam todo tipo de depressões, como dolinas, poljés, vales cegos, sumidouros, bem como campos de lapiás e epicarste, entre pequenas, médias e grandes feições. Já na segunda categoria observa-se a descarga, a saída da água do sistema, especialmente através das surgências, onde ocorreriam feições como planícies com relevos residuais, e feições de acumulação como represas de travertino e tufas, por exemplo. Apesar desta forma resumida de classificar as feições cársticas, os autores também citam inúmeras outras maneiras de classificar o carste: paleocarste, exumado, relicto, interestratal; intraestratal; exocarste, endocarste, criptocarste, hipercarste, hipocarste, carste barré, carste de contato; pseudocarste; termocarste; vulcanocarste; fluviocarste (FORD e WILLIAMS, 2007). 
Por fim, em síntese relativamente recente ao tratar do verbete "karst", Jones e White (2012), revisam diversos termos associados a tipologias específicas do carste. Ambientes dominados por dolinas são chamados de "carste de dolinas". De forma parecida ocorre o "carste de cones e torres" onde tais formas residuais predominam, as vezes sendo também chamados de carste de cockpit. Em paisagens de origem mista, ocorrem o fluviocarste, carste alpino e o glaciocarste. São citados ainda o carste costeiro, afetado pelas marés, ondas e tempestades, além da ação biogênica; o carste de zona de mistura, caraterizado pelo maior poder dissolutivo gerado na junção entre águas doces interiores e águas marinhas, mesmo ambas saturadas; o carste telogenético, que ocorre em rochas compactas continentais de baixa permeabilidade (fraturas e acamamento) e se opõe ao carste eogenético, caracterizado por calcários jovens, sem significativa ação diagenética, portanto de alta permeabilidade primária, encontrado em regiões litorâneas. O carste hipogênico se caracteriza pela dissolução ascendente por águas profundas, estimulada pela condição hidrotermal (carste hidrotermal) ou de acidez pela presença de sulfetos na composição das rochas (carste por ácido sulfúrico), dando origem a grandes sistemas de cavernas, como a Carlsbad e Lechuguila no Novo México.

Este tipo de carste, hipogênico, vem sendo foco de muitos estudos recentes, sobretudo em função da sua capacidade de formar grandes cavernas sem manifestações morfológicas em superfície, não sofrer interferências epigênicas em seu desenvolvimento e por ser um importante potencial armazenador de hidrocarbonetos (vide revisão de KLIMCHOUK, 2018). O maior sistema de cavernas da América do Sul, com 145km de galerias mapeados, entre a Toca da Boa Vista e a Toca da Barriguda (Campo Formoso, BA) é considerada uma feição hipogênica, possivelmente desenvolvida por hidrotermalismo muito antigo (AULER et al., 2017). A consistente diferenciação espeleogenética observada entre os processos hipogênicos (profundos; confinados) e epigênicos (mais superficial; não confinado hidraulicamente) juntamente com o entendimento de que estes processos morfogenéticos são os principais na configuração do carste, levou Klimchouk (2015) a propor esta forma inicial de classificação, em convergência e sem se opor ao já proposto anteriormente em parceria com Ford (KLIMCHOUK e FORD, 2000, vide Figura 1). Esta visão mais recente do autor se opõe a classificações mais antigas que segundo o mesmo estabeleceram um paradigma calcado sobretudo nas formas superficiais, epigênicas (exocarste e endocarste) e não em processos espeleogenéticos, considerado o principal fenômeno causador das formas típicas do carste, que podem inclusive ocorrerem em grande profundidade, sem ação de águas meteóricas, ou manifestações morfológicas na superfície, por exemplo. As principais tipologias do carste aqui descritas estão resumidas a seguir (Tabela 1), onde se observa a evolução das terminologias e conceitos ao longo do tempo.

Tabela 1 - Tipologias de carste propostas por autores ao longo do tempo.

\begin{tabular}{ll}
\hline Publicações & Tipologias de Carste \\
\hline Cvijić (1893) & Holocarste X Merocarste \\
\hline Roglic (1960) & Fluviocarste \\
\hline Williams (1972) & Poligonal (pináculos, torres, cones, cockpit, fluviocarste) \\
\hline Bögli (1980) & Exocarste X Endocarste \\
\hline Jennings (1985) & $\begin{array}{l}\text { Desnudo X Coberto; Fluviocarste; Livre X Aprisionado; Subjacente (ou interestratal); } \\
\text { Soterrado (fóssil) X Exumado; Relicto; Paleocarste; Biocarste }\end{array}$ \\
\hline Karmann (1994) & Poligonal (fluvial, contato, fluviocarstica, transição, poligonal) \\
\hline Piló (1998) & Exocarste X Epicarste X Endocarste \\
\hline Klimchouk e Ford (2000) & $\begin{array}{l}\text { Intraestratal (profundo, subjacente e entrincheirado); Desnudo; Exposto (aberto, } \\
\text { coberto, enterrado, exumado); Singenético }\end{array}$ \\
\hline Ford e Williams (1989; 2007) & $\begin{array}{l}\text { Formas de Recarga X Descarga; Outros tipos citados: paleocarste, exumado, relicto, } \\
\text { interestratal; intraestratal; exocarste, endocarste, criptocarste, hipercarste, hipocarste, } \\
\text { carste barré, carste de contato; pseudocarste; termocarste; vulcanocarste; } \\
\text { fluviocarste }\end{array}$ \\
\hline Jones e White (2012) & $\begin{array}{l}\text { Carste de Dolina; Carste de Cones e Torres; Carste de Origens Mistas (fluviocarste; } \\
\text { carste alpino; glaciocarste); Carste Costeiro; Carste de Zona de Mistura; Carste } \\
\text { Elimchouk (2015) }\end{array}$ \\
\hline ácido sulfúrico)
\end{tabular}




\section{EPICARSTE, IMPORTANTE ZONA MORFOGENÉTICA}

Algumas destas classificações cársticas incluem e consideram fortemente os processos morfogenéticos, especialmente a espeleogênese como o elemento impulsionador das formas que se manifestam em última análise em superfície. A compreensão da dinâmica de circulação hídrica no carste através das zonas hidrológicas (vadosa, oscilação do lençol e freática) e os produtos diferenciados da interação destes fluidos com a rocha, aumentando gradativamente a permeabilidade e o transporte de materiais é que permitem, eventualmente, a manifestação superficial dos fenômenos cársticos. Conforme Klimchouk e Ford (2000), se determinados tipos de feições cársticas são fundamentalmente superficiais, como lapiás em rochas expostas (rillenkarren), a essência deste sistema é a circulação subterrânea, criando vazios e cavernas na rocha solúvel. Depressões como dolinas e poljés, quando existentes, contribuem para suprir água ao sistema, mas não são essenciais para a circulação subterrânea. Ou como os autores definem assertivamente, "Se o carste está expresso na superfície, isso não é relevante. Um sistema cárstico pode operar no subsolo sem qualquer relação com a superfície, sendo representado exclusivamente por formas subterrâneas(...)" (KLIMCHOUK e FORD, 2000, p.46). Diante disso os autores ressaltam a importância no carste das zonas morfogenéticas subsuperficiais em detrimento unicamente da análise das expressões morfológicas superficiais para sua classificação.

Neste sentido, considerando o objetivo de se discutir e entender a formação de depressões cársticas, é necessário voltar a atenção a uma importante zona morfogenética destas paisagens, situada um pouco abaixo da superfície, o epicarste, responsável por até $80 \%$ da denudação química do sistema (FORD e WILLIAMS, 2007). Conforme Bakalowicz (2013), a inclusão do conceito de epicarste como importante zona morfogenética do carste é decorrente das discussões sobre o tema em âmbito mundial, entre as décadas de 1960/1970 através de trabalhos como o de Rouch (1964, apud BAKALOWICZ, 2013) e Mangin (1975, apud BAKALOWICZ, 2013), especialmente em função da sua importância hidrológica, biológica e ambiental. Neste sentido, o epicarste (KLIMCHOUK, 2000; FORD e WILLIAMS 2007), ou zona subcutânea (WILLIAMS, 1983) pode ser definido como a camada superficial de material mais intemperizado entre a rocha subjacente e o solo, que está particularmente exposta a ação dissolutiva e difusa das águas meteóricas e ao alargamento de descontinuidades, possuindo importante função de armazenamento e concentração de fluxos para a zona vadosa (Figura 2). O epicarste, juntamente com o solo (se existente) comporiam do ponto de vista hidrológico a zona vadosa, insaturada, que ainda possui uma zona de transmissão gravitacional lenta através do maciço rochoso para a zona freática, saturada (FORD e WILLIAMS, 2007; WILLIAMS, 2008; ver Tabela 2).

Tabela 2 - Zonas hidrológicas do carste.

\begin{tabular}{ll}
\hline Zona Insaturada (vadosa) & Solo \\
& Zona Epicárstica (ou subcutânea) \\
& Zona de Percolação Livre (transmissão) \\
\hline Zona Intermitentemente Saturada & Zona Epifreática (zona de flutuação do nível do aquífero) \\
\hline Zona Saturada (freática) & Zona Freática Superficial \\
& Zona Freática Profunda (batifreática) \\
& Zona Freática Estagnada
\end{tabular}

Fonte - Adaptado de FORD e WILLIAMS (2007, p. 107).

Segundo Palmer (2007), o epicarste seria essencialmente a extensão subsuperficial dos lapiás. Para Bakalowicz (2012) o epicarste é o setor chave para a dissolução dos carbonatos, por sua relação tão próxima à principal fonte de $\mathrm{CO}^{2}$, o solo. Consequentemente, segundo o mesmo autor, o carste se desenvolve e evolui como resultado do epicarste, criando feições superficiais como lapiás e dolinas, bem como subsuperficiais, como condutos e cavernas. Pode ser, portanto, entendido como a mola propulsora das feições cársticas, dentre elas as depressões. Para Zwahlen (2004), que considerou fortemente a questão da vulnerabilidade dos aquíferos nestes ambientes, feições cársticas superficiais são apenas a expressão do desenvolvimento do epicarste e podem nem sempre se apresentarem visíveis através de formas como dolinas ou campos de lapiás, apesar destas feições serem indicadores geomorfológicos da sua operação. 
Figura 2 - O epicarste e uma dolina soterrada, ou criptodolina, representadas em uma mineração em Bacaetava-PR. Sistema interligado à semidestruída Gruta dos Cinco Níveis. Manchas alaranjadas representando zonas de maior alteração ou sedimentação.

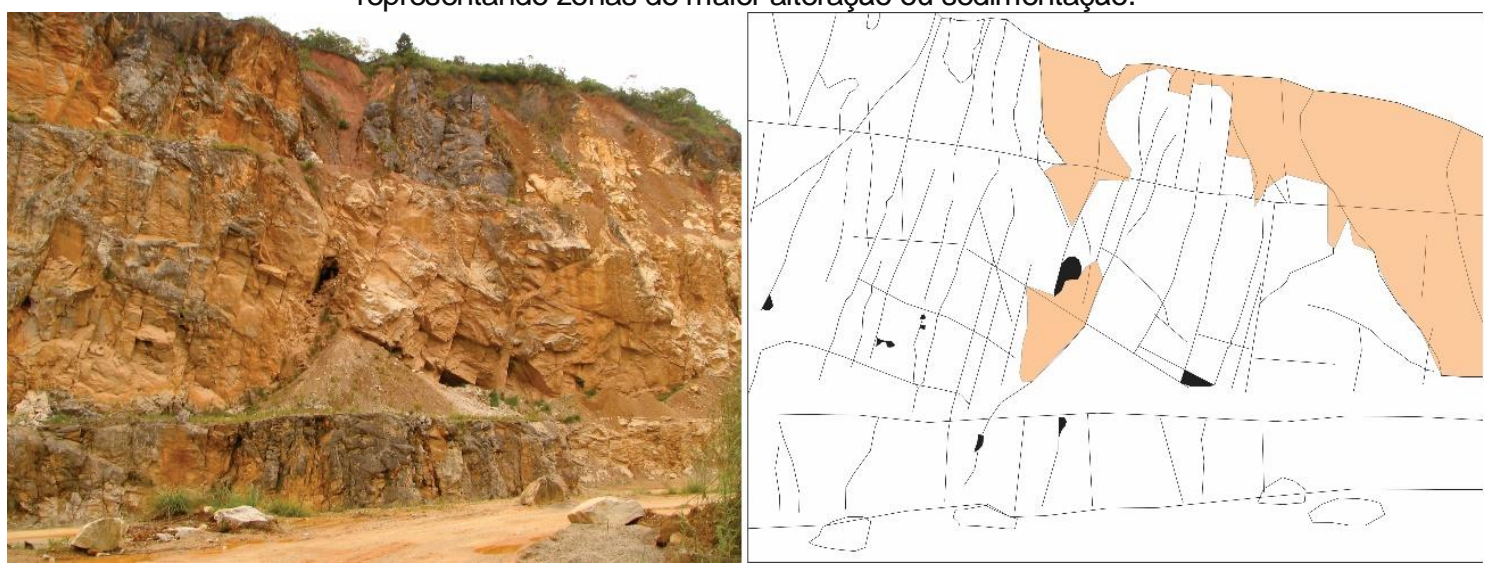

Fonte - Foto (2006) e esquema do autor.

\title{
DOLINA - A DEPRESSÃO CÁRSTICA ELEMENTAR
}

Esta revisão dará maior destaque aos processos e formas correspondentes das dolinas, por serem consideradas feições elementares do carste, comparáveis a bacias de primeira ordem (SAURO, 2012) ou até mesmo formas diagnósticas (CVIJIĆ, 1890, apud FORD, 2007). Bondesan et al. (1992) consideram que cada dolina corresponde a uma unidade hidromorfológica funcional. Para outros autores as dolinas são consideradas feições indicadoras (FORD e WILLIAMS, 2007), pois este tipo de sistema se desenvolve mesmo sem a ocorrência de depressões em superfície (WILLIAMS, 2004). Ou seja, se há dolina, há carste, sendo o contrário nem sempre verdadeiro. As demais depressões cársticas como dolinas compostas (uvalas), poljés e as microformas (kamenitzas, p.ex.), apesar de circunstancialmente comungarem de processos equivalentes, não serão tradadas pormenorizadamente nesta oportunidade. Importante ressaltar, porém, que dolinas podem ocorrer inclusive no interior de grandes depressões compostas, poligonais ou mesmo poljés, demonstrando seu caráter elementar no desenvolvimento destas paisagens.

Se a natureza do sistema cárstico é o fluxo subterrâneo, incluindo o transporte de materiais em dissolução ou desagregação mecânica, é natural que então surjam na superfície depressões fechadas, sem conexão superficial com a rede de drenagem (PALMER, 2007). Como coloca Williams (2004), o desenvolvimento de qualquer tipo de dolina depende da capacidade da água infiltrar e fluir através de rochas cársticas até as ressurgências. No Brasil distingue-se estas depressões cársticas normalmente entre dolinas - de menor tamanho; uvalas - quando duas ou mais dolinas se coalescem; e poljés - grandes depressões aplainadas de drenagem fechada. Apesar da relativa e aparente facilidade de diferenciação teórica entre estes tipos, inúmeros processos e às vezes complexos mecanismos se inter-relacionam de tal forma a resultar na expressão superficial deprimida, nem sempre perfeita e de fácil distinção. Um pouco desta complexidade está manifestada na definição de dolina de Beck (2012):

\begin{abstract}
"As dolinas (sinkholes) são as expressões superficiais (e quase superficiais) do processo interno de drenagem e erosão em terrenos cársticos, geralmente caracterizados por depressões na superfície terrestre. Os processos formativos incluem a dissolução de camadas de rocha, o transporte descendente do excesso de sedimentos e/ou o colapso do leito rochoso. A maioria das grandes dolinas maduras tem uma origem complexa envolvendo todos os três processos. Em alguns estágios no desenvolvimento de dolinas, uma depressão de superfície pode não estar presente" (BECK, 2012, p. 723).
\end{abstract}

Percebe-se nesta definição, em convergência ao que postularam Klimchouk e Ford (2000) que nem sempre as depressões estão expressas na superfície, apesar dos processos cársticos operarem em subsuperfície (Figura 2). Ou conforme Sauro (2012), a estrutura de uma dolina começa a se desenvolver antes mesmo do início da depressão superficial. Outro fator importante desta definição, sobretudo no contexto tropical brasileiro de grande quantidade de material superficial (solo, regolito), 
processos biogeomórficos e pluviosidade, é a questão da poligenia das dolinas. Apesar de existirem mecanismos iniciais de desenvolvimento e formas típicas resultantes, estes sinais podem ser completamente apagados ou eclipsados por processos posteriores.

Ford e Williams (2007) apresentam uma revisão importante sobre poljés, caracterizados por serem grandes depressões fechadas aplainadas pela atividade de migração lateral fluvial, geralmente com um dos lados da bacia proeminente (escarpado), drenagem subterrânea em alguns pontos e uma característica proximidade do nível do aquífero com a superfície. Sauro (2012) faz uma curta revisão sobre poljés e também sobre depressões compostas, termo que o autor utiliza em substituição a uvala, considerado por ele e outros autores (PALMER, 2007, GUTIERREZ et. al. 2014), um termo em desuso que merece melhor definição, ou que se aplicaria a casos mais restritos, como sistemas de falhas locais acelerando a dissolução (ver ĆALIC, 2011). Apesar da indefinição internacional acerca do termo, em virtude da crítica à teoria dos ciclos davisiana na qual Cvijić deixou a entender que dolinas evoluiriam para uvalas e estas para poljés (ver esta discussão em KRANJC, 2013), o termo uvala continua sendo muito usado no Brasil.

\section{PROCESSOS DE FORMAÇÃo}

Os processos de formação de dolinas envolvem diferentes aspectos, tanto relacionados aos mecanismos erosivos (dissolução ou ação mecânica), tempos diferenciados (geológico, histórico ou repentino) como materiais distintos (coberturas móveis, rocha carstificável ou não). A dinâmica dos processos de formação e desenvolvimento de dolinas é caracterizada por diversos autores principalmente entre, dissolução, colapsos e subsidências (JENNINGS, 1985; FORD e WILLIAMS, 2007; BECK, 2012; ver Figura 3). Entretanto observa-se na literatura entendimentos diferentes para aplicações destes termos, como subsidência, e algumas inclusões de conceitos similares ou adicionais. Em virtude destas diferentes abordagens entre autores ao longo dos anos para classificação genética das dolinas, algumas sínteses das propostas foram realizadas, destacando-se a de Williams (2004) e Waltham et al. (2005).

Buscando atualizar tais sínteses com publicações mais recentes é apresentada aqui as propostas internacionais de classificação (Tabela 3). Adiante serão detalhados os mecanismos de formação de dolinas e suas especificidades, sem considerar os aspectos morfológicos, que serão tratados no tópico subsequente. Vale ressaltar, entretanto, o caráter poligenético e simultâneo de processos em boa parte das depressões encontradas na natureza, especialmente em ambientes tropicais, o que torna o esforço de simplificação uma aproximação, sobretudo, teórica. Ou como pontuam Cahalan e Milewski (2018), as dolinas se formam em função da interação complexa de fatores como os hidrológicos (inundações, p.ex.), geológicos (espessura das camadas, p.ex.), geomorfológicos (elevação, p.ex.), antropogênicos (uso do solo, p.ex.), climáticos (regime de precipitação, p.ex.), hidrogeológicos (flutuação do aquífero, p.ex.), ou outros fatores (resistência geotécnica do solo, p.ex.) que agem em magnitudes variáveis e escalas de tempo/espaço distintas.

Figura 3 - Tipologia de dolinas adaptada de Waltham e Fookes (2005).

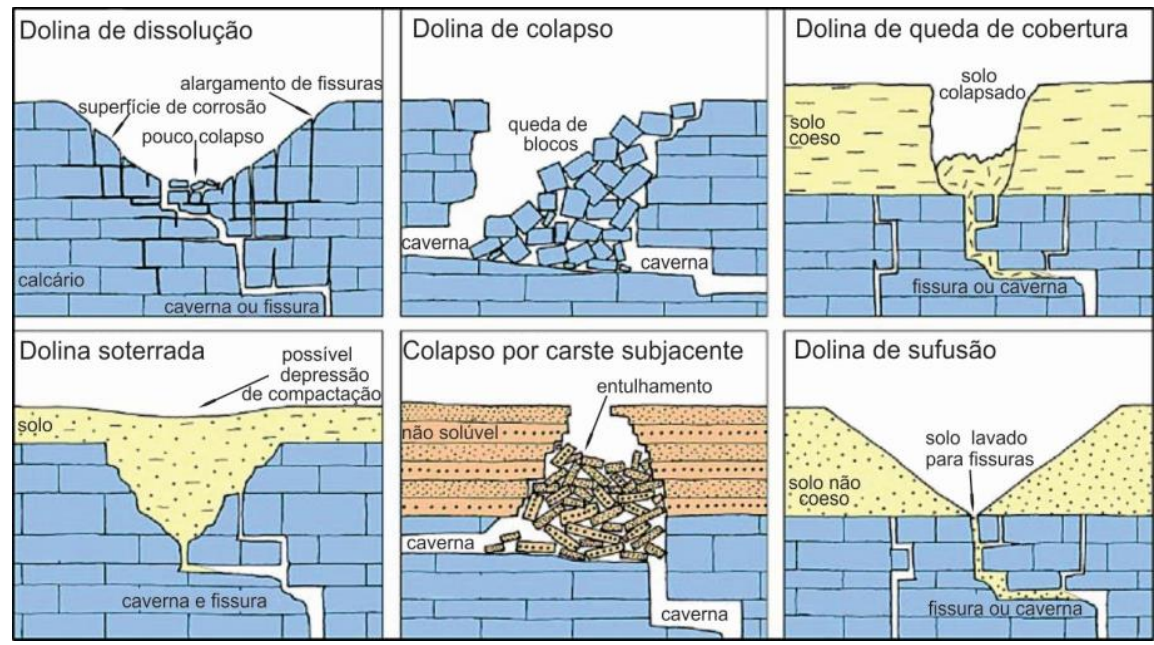

Fonte: WALTHAM e FOOKES (2005). 
Tabela 3 - Tipologia de dolinas e processos por autores. Separação de subgrupos identificados pelos próprios autores: ${ }^{1}$ tempo permanente na paisagem; ${ }^{2}$ tempo humano na paisagem; ${ }^{3}$ grupo colapso; ${ }^{4}$ grupo subsidência; ${ }^{5}$ grupo dissolução; ${ }^{6}$ outros tipos.

\begin{tabular}{|c|c|c|c|c|c|c|c|c|c|c|c|}
\hline \multicolumn{2}{|c|}{$\begin{array}{l}\text { Tipologia de dolinas por } \\
\text { autores }\end{array}$} & $\begin{array}{c}\text { Sweeting } \\
\text { (1972) }\end{array}$ & $\begin{array}{c}\text { Bögli } \\
(1980) \\
\end{array}$ & Jennings (1985) & White (1988) & Williams (2004) & $\begin{array}{c}\text { Whaltham et al. } \\
(2005)\end{array}$ & $\begin{array}{c}\text { Ford \& Williams } \\
(2007)\end{array}$ & Beck (2012) & Sauro (2012) & $\begin{array}{l}\text { Gutierrez et al. } \\
\text { (2014) }\end{array}$ \\
\hline \multirow{2}{*}{\multicolumn{2}{|c|}{ Dolinas de dissolução }} & Dissolução & Dissolução & Dissolução & 'Dissolução' & Dissolução & Dissoluçãa & Rebaixamento & \multirow[t]{3}{*}{ Dissolução } & Rebaixamento $^{5}$ & \multirow[t]{3}{*}{ Dissoluçãa ${ }^{5}$} \\
\hline & & & & & & & & Ponto de recarga & & Ponto de recarga ${ }^{5}$ & \\
\hline & & & & & & & & & & Absorçãa $0^{5}$ & \\
\hline \multirow{2}{*}{ 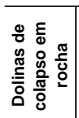 } & Solúvel & Colapso & $\begin{array}{l}\text { Colapso } \\
\text { (rápido) }\end{array}$ & Colapso & Colapso' & Colapso $^{3}$ & Colapso & Colapso $^{3}$ & $\begin{array}{l}\text { Colapso de } \\
\text { camada de } \\
\text { rocha }\end{array}$ & Colapso $^{6}$ & Colapso $^{4}$ \\
\hline & Não solúvel & Subsidencia & $\begin{array}{l}\text { Subsidência } \\
\text { (lenta) }\end{array}$ & $\begin{array}{l}\text { Colapso por carste } \\
\text { subjacente }\end{array}$ & & $\begin{array}{l}\text { Colapso de rocha } \\
\text { sobrejacente }^{3}\end{array}$ & $\begin{array}{l}\text { Colapso de rocha } \\
\text { sobrejacente }\end{array}$ & $\begin{array}{l}\text { Colapso de rocha } \\
\text { sobrejacente }^{3}\end{array}$ & & & $\begin{array}{l}\text { Colapso de rocha } \\
\text { sobrejacente }^{4}\end{array}$ \\
\hline \multirow{3}{*}{ 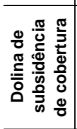 } & Colapso & & & & $\begin{array}{l}\text { Colapso de } \\
\text { cobertura }^{2}\end{array}$ & \multirow{3}{*}{$\begin{array}{c}\text { Queda de } \\
\text { cobertura } \\
\text { Sufusãa e } \\
\text { subsidencia de } \\
\text { cobertura }\end{array}$} & $\begin{array}{l}\text { Queda de } \\
\text { cobertura }^{4}\end{array}$ & $\begin{array}{l}\text { Queda de } \\
\text { cobertura }^{3}\end{array}$ & $\begin{array}{l}\text { Colapso de } \\
\text { cobertura }^{4}\end{array}$ & Cobertura $^{6}$ & \multirow{3}{*}{$\begin{array}{l}\text { Colapso de } \\
\text { cobertura }^{4} \\
\text { Sufusão de } \\
\text { cobertura }^{4}\end{array}$} \\
\hline & Sufusão & Aluvial & Aluvial & Subsidência & $\begin{array}{l}\text { Subsidência } \\
\text { de cobertura }{ }^{2}\end{array}$ & & Sufusão ${ }^{4}$ & $\begin{array}{l}\text { Subsidência e } \\
\text { sufusão }\end{array}$ & $\begin{array}{l}\text { Subsidencia } \\
\text { de cobertura }^{4}\end{array}$ & Cobertura $^{6}$ & \\
\hline & Soterramento & & & & & & Soterrada & & Soterrada & Embrionária & \\
\hline \multirow{3}{*}{ 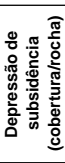 } & \multirow{3}{*}{$\begin{array}{l}\text { Acomodamento } \\
\text { (evaporitos } \\
\text { principalmente) }\end{array}$} & & & & & \multirow[t]{3}{*}{$\begin{array}{l}\text { Depressão } \\
\text { regional de } \\
\text { subsidência }\end{array}$} & & & & \multirow[t]{3}{*}{$\begin{array}{c}\text { Subsidência } \\
\text { (acomodamento })^{6}\end{array}$} & $\begin{array}{l}\text { Acomodamento } \\
\text { de rocha } \\
\text { sobrejacente }^{4}\end{array}$ \\
\hline & & & & & & & & & & & $\begin{array}{l}\text { Acomodamento } \\
\text { cobertura }\end{array}$ \\
\hline & & & & & & & & & & & $\begin{array}{c}\text { Acomodamento } \\
\text { na própria rocha }{ }^{4}\end{array}$ \\
\hline $\begin{array}{l}\text { Outros } \\
\text { tipos }\end{array}$ & & & & $\begin{array}{c}\text { Dolina de } \\
\text { sumidouro aluvial }\end{array}$ & & & & & & $\begin{array}{c}\text { Interseção } \\
\text { (paleocarste) }^{6}\end{array}$ & \\
\hline
\end{tabular}

\section{A DISSOLUÇÃO ABRINDO CAMINHO}

As depressões cársticas possuem íntima relação com os processos hidrológicos e dissolutivos que ocorrem em subsuperfície desencadeando outros processos erosivos. Segundo Klimchouk (1995), o desenvolvimento de dolinas na superfície se deve principalmente aos mecanismos de morfogênese do epicarste, desde que a recarga autogênica e difusa prevaleça em detrimento à corrosão por concentração de fluxos em superfície através dos pontos de recarga. Conforme a figura elaborada por Williams (1983), observa-se a fundamental importância da zona epicárstica neste processo (Figura 4). À medida que a água enriquecida com ácidos carbônicos da atmosfera e do solo percola pelo pacote rochoso fraturado, a dissolução vai então alargando gradativamente as descontinuidades. Este processo epicárstico é especialmente mais importante entre os 3 e 10 metros de profundidade, visto que a solução antes acidulada vai entrando em equilíbrio e perdendo seu poder corrosivo (WILLIAMS, 1983; 2008; KLIMCHOUK, 1995; KLIMCHOUK et al., 1996; FORD e WILLIAMS, 2007; JONES e WHITE, 2012). A maior parte da água não pode escoar livremente para baixo em virtude do afunilamento destas aberturas verticais, criando o que Williams (1983) chamou de barreira de capilaridade, responsável pela manutenção de um aquífero suspenso cujo excedente hídrico passa então a movimentar-se lateralmente. A presença de setores mais fraturados ou alargados em subsuperfície criam zonas preferenciais de escoamento vertical, aumentando a permeabilidade e a partir disso, num processo de feedback positivo, há um aumento da dissolução e consequente perda de material para setores mais profundos da zona vadosa, criando assim um ponto preferencial de desenvolvimento de uma dolina a partir do rebaixamento do aquífero epicárstico. Tais depressões seriam formadas por fluxos centrípetos em pontos focados de grande permeabilidade no epicarste, explicando assim o padrão preferencialmente circular destas feições. Em convergência a este modelo, Klimchouk et al. (1996) enfatizam o desenvolvimento oculto de condutos verticais, ou hidden shafts do inglês, que ocorrem na base da zona epicárstica normalmente sem conexão direta com a superfície, mas de grande importância para a concentração dos fluxos, direcionamento da espeleogênese e formação de depressões.

Outro processo importante de desenvolvimento por dissolução, descrito por Ford e Williams (2007) e Sauro (2012), ocorre pela iniciação de dolinas por pontos de recarga, quando há a captura da drenagem superficial em camadas não solúveis (água alogênica) por sistemas de proto cavernas subjacentes em camadas carstificáveis, como calcários. O entalhe fluvial pode criar uma janela de exposição para a rocha solúvel, a partir da qual passa a ocorrer a infiltração pontual em determinadas estruturas favoráveis e alargamento de um proto conduto. $O$ avanço vigoroso do entalhe nos calcários por cursos principais adjacentes estabelece diferenciações altimétricas entre a recarga e descarga, e se a dissolução nas estruturas da rocha permite a conexão entre ambas as áreas, a maior permeabilidade leva ao aumento da remoção dos materiais químicos e clásticos. A partir do momento que se estabelece a interconexão entre este ponto de recarga alogênica para a descarga, se origina então gradativamente uma dolina de drenagem centrípeta, logo, circular. 
Figura 4 - O epicarste, ou zona subcutânea, representado por Williams (1983), mostrando a importância intrínseca desta zona morfogenética na evolução de dolinas de dissolução.
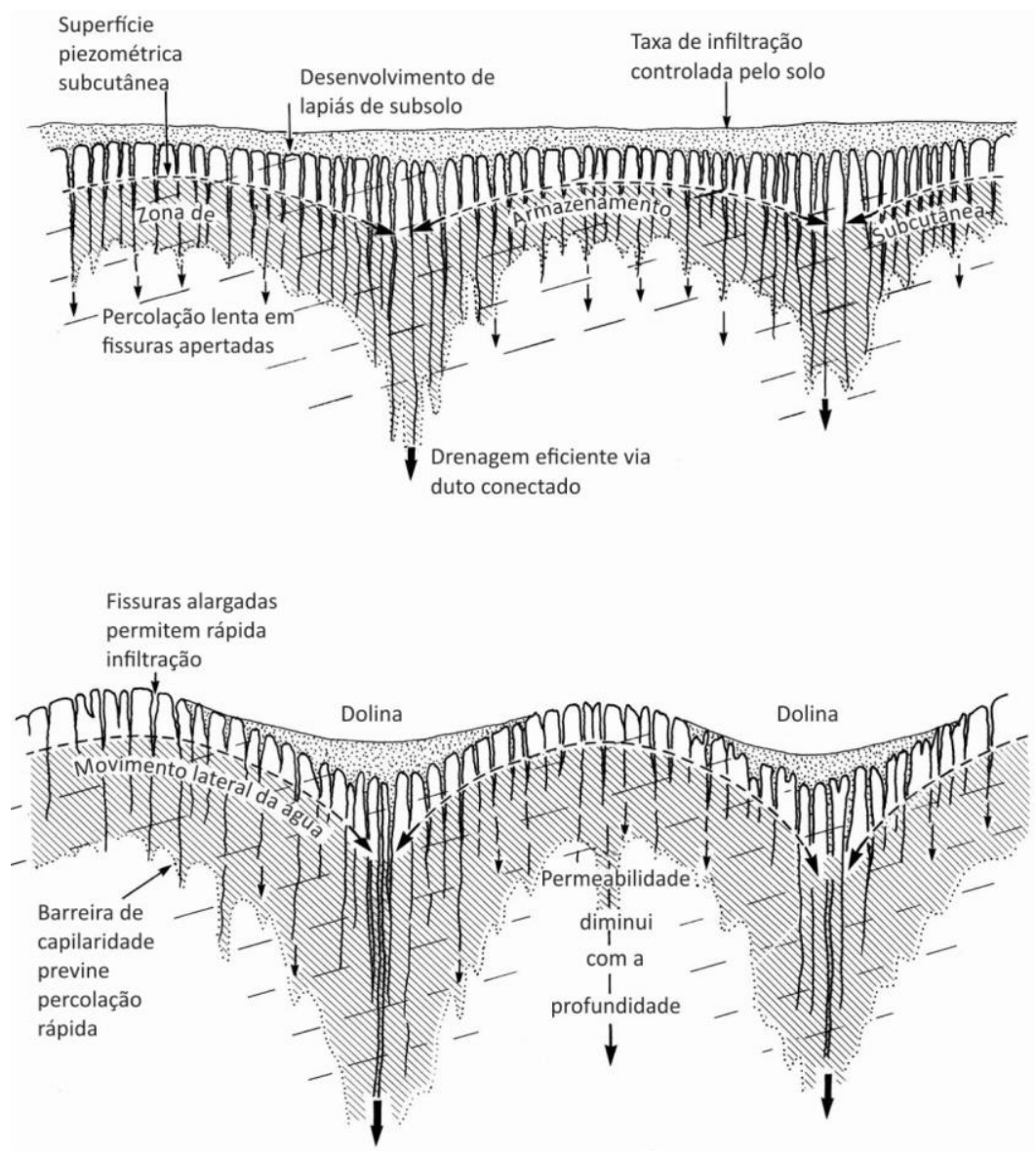

Fonte - adaptado da figura apresentada por WILLIAMS (2008).

Com base nestes processos espeleogenéticos que ocorrem no epicarste e pontos de recarga, outros processos passam a operar em contribuição à diferenciação morfológica das depressões que se manifestam na superfície. Segundo Beck (2012), as diversas formas de dolinas em carbonatos são determinadas por apenas dois mecanismos principais, sendo o primeiro o transporte de material superficial através de canais alargados pela dissolução e o segundo o colapso de camadas acima (teto) de grandes cavidades. A evolução e interconexão dos aparatos subterrâneos de drenagem com a superfície favorecem o fluxo livre da água e o transporte de materiais. $O$ primeiro e mais importante deles é o próprio mineral solúvel ( $\mathrm{CaCo}^{3}$ nos carbonatos), dando origem às depressões mais puras no carste, as dolinas de dissolução, em geral com pouca ou nenhuma cobertura sobre as rochas, que se apresentam preferencialmente desnudas. A dissolução alarga as descontinuidades, desmonta e separa os blocos de rocha, podendo levar à instabilidade de camadas superiores ou vazios subsuperficiais. Por outro lado, coberturas superficiais como solo e sedimentos, quando existentes, passam a ser capturados para o subterrâneo de formas diferenciadas, a depender da coesão dos materiais, como será tratado a seguir.

\section{SUBSIDÊNCIAS LENTAS DE MATERIAL}

A presença de coberturas móveis sobre rochas carstificadas pode levar ao processo de erosão vertical através de juntas alargadas ou condutos de dissolução subjacentes, como já demonstrado na discussão sobre epicarste, num processo misto entre dissolução e erosão mecânica. Tal processo ocorre de forma gradual, lenta, através da infiltração da água nestas estruturas e é chamada de subsidência (BECK, 2012). Alguns autores chamam tais dolinas de aluviais (CVIJIĆ 1890 apud FORD 2007; BÖGLI, 1980) ou dolinas de "sufusão" (FORD e WILLIAMS, 2007). Este processo é especialmente importante em áreas de espessas camadas de material que recobre as rochas 
cársticas. Tais materiais podem ser solos residuais (argila de descalcificação p. ex.), sedimentos (colúvios, alúvios, etc.) ou mesmo material intemperizado in situ de outras rochas que recobriam a área. Dolinas de subsidência lenta de cobertura são mais comuns quando o material apresenta uma menor coesão (silto-arenosos, por exemplo), permitindo o transporte gradual e não repentino.

Vários autores relacionam este processo de subsidência que ocorre em materiais inconsolidados através da infiltração gradual de água e a lavagem de sedimentos finos por condutos presentes na base das depressões como "dolina de sufusão", ou "suffosion dolines" (WILLIAMS, 2004; WHALTHAM et al. 2005; FORD e WILLIAMS, 2007; GUTIERREZ et al. 2014). Possivelmente pela falta de uma tradução mais adequada para o português, no Brasil convencionou-se a adotar o termo dolina de subsidência ou dolina aluvial (p. ex. PILÓ, 2000; BIGARELA et al., 1994) para este mesmo processo descrito para as dolinas de sufusão. Conforme a síntese dos termos aqui apresentada (Tabela3) verifica-se que não há de fato uma uniformização da terminologia utilizada para classificar esta tipologia de dolina em que processos mecânicos de erosão auxiliam a conformação da depressão além da dissolução. Utilizar apenas o termo subsidência para este processo pode causar confusão uma vez que o conceito é mais amplo e utilizado como um descritor inicial para outros processos. Gutierrez et al. (2014) utilizam o termo subsidência coletivamente para todos os demais tipos específicos de dolinas, à exceção das dolinas de dissolução.

Ford e Williams (2007), por exemplo, consideram que dolinas de subsidência ideais seriam aquelas que se formam pelo acomodamento gradual da superfície causado pela dissolução das camadas subjacentes sem rupturas ou fraturamentos significativos, apesar de que na prática haja uma continuidade natural com ocorrências de eventuais quebras e deformações a depender da coesão da rocha/solo. Williams (2004) chama estas feições de depressões regionais de subsidência, mais suaves e ligadas em geral aos evaporitos, grandes demais para serem denominadas de dolinas. De forma parecida Gutierrez et al. (2014) defendem que diferentemente de outras rochas mais rúpteis, como os calcários, os evaporitos apresentam um caráter mais dúctil, de flexionamento das camadas acima dos vazios, processo chamado em inglês de "sagging", podendo formar grandes depressões na casa das centenas de metros de diâmetro. Sauro (2012) também propõe um tipo similar deste processo de acomodamento de rocha por subsidência através da dissolução de camadas inferiores solúveis recobertas por rochas insolúveis (arenitos p.ex.), gerando grandes depressões, as vezes com lagos. Entretanto este tipo de processo de subsidência ideal é mais relacionado a rochas evaporíticas e pouco comum no mundo, sobretudo no Brasil, apesar que em algumas regiões de carste recoberto por arenitos, como no Grupo Urucuia no oeste da Bahia, se notem grandes e suaves depressões, aparentemente deste tipo.

O desenvolvimento de uma proto dolina, com o alargamento das estruturas da rocha de forma a permitir o transporte de sedimentos clásticos forma um cone ou bacia que impõe um gradiente local e a captura preferencial de material para este ponto. Isso define a grosso modo a dolina de subsidência por sufusão já comentada. Entretanto, conforme descreve Beck (2012), quando as estruturas carstificadas da rocha são menos efetivas na condução dos sedimentos para o subterrâneo que a produção superficial dos mesmos, a dolina é paulatinamente preenchida, formando primeiramente depressões rasas, pântanos, pequenos lagos e acúmulo de material orgânico. O completo preenchimento da depressão define o que é chamado por alguns autores como dolina soterrada, sendo no Brasil também conhecidas por dolinas colmatadas. Sauro (2012), ao utilizar-se dos termos "criptodolina embrionária" ou "dolina de subsolo", propostos por Nicod (1975, apud SAURO, 2012), ressalta que tais feições podem armazenar paleosolos funcionando como armadilhas de sedimentos desde o início de sua formação, podendo nunca ter formado depressão superficial significativa (Figura 2). De toda maneira, tais dolinas soterradas/colmatadas, de difícil identificação, podem continuar operando de forma invisível em subsuperfície, como um mecanismo erosivo típico do carste, que denota sua maior fragilidade e risco.

\section{OS COLAPSOS (SOLOE ROCHA)}

Os colapsos ocorrem por conta da presença e migração vertical de vazios subterrâneos até a superfície, seja na própria rocha solúvel, subjacente em rochas não solúveis ou no solo. Alguns processos podem desencadear os colapsos na rocha, como por exemplo: o contínuo alargamento freático e aumento da cavidade até que o suporte mecânico das camadas superiores se perca; a drenagem de câmaras anteriormente alagadas e consequente perda de flutuabilidade da rocha, ou; 
a dissolução preferencial em zonas vadosas acima do teto de cavernas, através de fissuras, acamamento e condutos verticais, fragilizando o pacote rochoso (WHITE e WHITE, 2000; FORD e WILLIAMS, 2007). Palmer (2007) concorda que a drenagem de passagens subterrâneas antes alagadas e a eliminação do fator flutuabilidade leva ao acréscimo de peso efetivo no teto das cavernas, lembrando que o calcário possui densidade de $2,7 \mathrm{~g} / \mathrm{cm}^{3}$, mas em condições freáticas esta densidade equivaleria a apenas a $1,7 \mathrm{gr} / \mathrm{cm}^{3}$. Segundo o mesmo, a progradação do colapso de camadas de teto em cavernas pode alcançar centenas de metros para cima, ultrapassando inclusive camadas de rocha não solúveis e por fim atingindo a superfície. Estas seriam as dolinas de colapso por carste subjacente (JENNINGS, 1985) ou dolinas de colapso de rocha sobrejacente (não solúvel), do inglês, caprock (WILLIAMS, 2004; WALTHAM et al., 2005; FORD e WILLIAMS, 2007). Beck (2012) ressalta o componente misto nestas rupturas, ou seja, o alargamento cada vez maior da caverna e ao mesmo tempo a dissolução superficial diminuindo a espessura da camada superior até que ocorra a convergência deste processo, gerando o colapso.

Processos por colapso também atingem materiais inconsolidados presentes na superfície de rochas carstificadas, especialmente solo, sedimentos ou material intemperizado (regolito). Segundo Beck (2012), quando o material de cobertura se apresenta mais coeso (silto-argiloso, p.ex.), o vazio criado pela drenagem e erosão subsuperficial pode propagar para cima na forma de um arco através de conduto vertical (shaft). Com o tempo este mecanismo leva ao aumento do vazio e o material que colapsa neste processo pode se acumular na base ou ser transportado pelo sistema de drenagem oculta. A migração vertical deste processo pode atingir uma camada ainda mais coesa (argila p. ex.) e causar uma temporária resistência, levando por outro lado ao alargamento do vazio em detrimento da verticalização. Se este processo ocorre até próximo à superfície, uma camada fina e pouco resistente pode não suportar mais o seu próprio peso e colapsar abruptamente, formando então uma dolina de colapso em cobertura. Se o processo de colapso no meio rochoso raramente é abrupto e catastrófico (PALMER, 2007), no solo este processo pode ser bem dinâmico e causar danos consideráveis em estruturas como estradas e edificações (BECK, 2012). Por este motivo White (1988) considera as dolinas de colapso em rocha e de dissolução feições permanentes da paisagem na escala de tempo humano por sua lenta evolução, ao passo que as de subsidência e colapso de cobertura seriam feições dinâmicas, que podem se formar instantaneamente, em horas ou dias.

Estes processos de colapso descritos acima podem ocorrer, tanto na rocha como especialmente em materiais inconsolidados em função da variação do nível do aquífero local. Segundo Ford e Williams (2007), a variação sazonal do aquífero entre períodos úmidos e secos além das inundações temporárias pelo sifonamento de condutos em eventos de fortes chuvas podem causar mudanças repentinas no padrão de estresse de maciços carstificados ou no solo. Variações do nível do aquífero, segundo os autores citados, podem alcançar em algumas regiões até 100 metros verticais. Quando materiais inconsolidados são afetados por essa variação, especialmente quando do rebaixamento do aquífero, uma compressão pode ocorrer e levar tanto à subsidência como ao colapso, a depender da coesão dos materiais, como já mencionado. Um exemplo deste fenômeno é descrito por Hyatt e Jacobs (1996), quando 312 dolinas de colapso se formaram em decorrência de uma única inundação que se aproximou do intervalo de recorrência de 500 anos na bacia do rio Flint, Geórgia (EUA). Considerando que tais fenômenos ocorrem frequentemente influenciados por processos antrópicos, como bombeamento de água subterrânea ou alterações na configuração hídrica superficial, e considerando também o risco para áreas edificadas, infraestruturas e perda de vidas humanas, vários trabalhos se dedicam a estes processos em áreas cársticas (VENI et al., 2001; LOLCAMA et al., 2002; DELLE ROSE et al., 2004; WALTHAM e FOOKES, 2005; CARAMANNA et al., 2008; GUTIERREZ et al., 2008; 2014; DEL PRETE et al., 2010; COOPER et al., 2011; HEIDARI et al., 2011; SISKA et al., 2016).

\section{OUTROS PROCESSOS GERADORES DE DEPRESSÕES FECHADAS}

No trabalho de Ford e Williams (2007) observa-se uma parte dedicada a discussão de feições cársticas em outras tipologias de rocha, sobretudo as siliciclásticas, nas quais também ocorrem

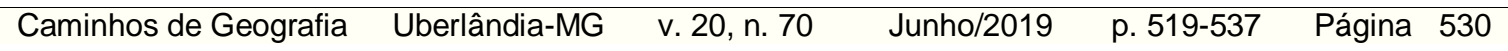


feições correspondentes ao carste carbonático, como drenagens subterrâneas, cavernas, lapiás, formas residuais e, em especial, depressões fechadas. Entretanto, os processos são um pouco diferentes, por isso aqui enquadradas em outras tipologias. Muito da discussão neste âmbito paira entre a preponderância de processos dissolutivos versus a ação mecânica de remoção de materiais, como piping. Embora minerais como a sílica ou os feldspatos sejam menos solúveis do ponto de vista geoquímico, em condições tropicais úmidas estes processos podem ocorrer de forma mais acentuada, sobretudo através de grandes sistemas de descontinuidades, como a intercessão entre fraturas e acamamento da rocha. Desta maneira podem se instalar processos epicársticos incipientes contribuidores na formação de um carste pouco evoluído se comparado ao carbonático, com decisiva contribuição de fatores mecânicos de erosão. Como exemplo, o intemperismo através dos interstícios promove a transformação de quartzitos em arenitos neoformados ("neosandstone", MARTINI, 2004), com a liberação dos grãos para o transporte físico. A menor propensão à dissolução e infiltração para o subterrâneo leva por consequência a ambientes predominantemente fluviais em transição ao fluviocarste. O intemperismo prévio e prolongado juntamente com a inserção de drenagens com grande gradiente (borda de planaltos p.ex.) favorecem a configuração de tais ambientes.

Igualmente, dolinas em ambientes siliciclásticos por consequência são muito observadas em áreas de relevo mais acentuado, como bordas de planaltos. Podem ocorrer dolinas de subsidência (sufusão) e colapsos relacionados a cavernas próximas a superfície. Segundo Ford e Williams (2007), a ocorrência de dolinas de dissolução em tais ambientes parece ser inexistente, visto que não há o desenvolvimento completo de um epicarste, conforme já demostrado para dolinas carbonáticas, embora os processos dissolutivos ocorram e tomem parte importante neste processo.

Em alguns trabalhos são citados outros processos de formação de dolinas, desde as induzidas pelo homem já relatadas ou até mesmo dolinas desenvolvidas por processos de piping profundo, como as descritas para a Itália por Caramanna et al. (2008), em que a propagação de vazios em grande profundidade em espessos depósitos fluviais parece ser induzida por eventos sísmicos e vulcanismo.

\section{CLASSIFICAÇÃo AJUSTADA}

Após realizar a revisão detalhada das classificações de dolinas entre os vários autores arrolados (Tabela 3), foi possível ajustar uma síntese que será descrita a seguir. Algumas tipologias de dolinas são citadas por todos, como as de dissolução e colapso em rocha solúvel. Outras terminologias apresentam aplicações mais complexas, sobretudo as que envolvem o termo subsidência. Desta forma foi necessário resumir esta interpretação da literatura, sobretudo com base na diferenciação dos mecanismos e produtos resultantes.

O primeiro tipo, as "dolinas de dissolução", caracterizam-se por pouca ou nenhuma cobertura, normalmente encontrada nas partes altas do relevo cárstico, como planaltos ou morrotes desnudos e lapiazados, nas quais a remoção dos materiais inconsolidados é mais acentuada pelo epicarste raso. Um segundo tipo de dolina ocorreria decorrente dos colapsos de rocha no teto de grandes cavernas no subterrâneo, seja na própria litologia solúvel ou outra sobrejacente, insolúvel, resultando em dois subtipos: "dolina de colapso em rocha solúvel" e "dolina de colapso por carste subjacente". Já as dolinas de subsidência de cobertura podem se subdividir entre: "dolina de subsidência de cobertura por colapso"; "dolina de subsidência de cobertura por sufusão" e; "dolina de subsidência de cobertura por soterramento". Entre as duas primeiras de subsidência de cobertura observa-se um corte temporal abrupto ou gradual, respectivamente, em função da coesão dos materiais móveis. $O$ tipo "soterrada" (ou colmatada) pode ter uma taxa de transferência de materiais para o subterrâneo inferior a seu preenchimento superficial, mas ainda assim ativa, embora nem sempre visível na superfície. Um tipo final, pouco recorrente no Brasil, mais atribuídas a rochas evaporíticas, seria a "depressão de subsidência por acomodamento", que geram grandes e suaves dolinas e ocorrem por dissolução interestratal podendo afetar rochas ou coberturas. Dolinas mais específicas são temporariamente acomodadas no grupo "outros tipos". Uma simplificação desta interpretação pode ser observada na figura a seguir (Figura 5). 
Figura 5 - Tipos de dolina simplificado. Em cinza os processos dominantes.

\section{Dolina de Dissolução}

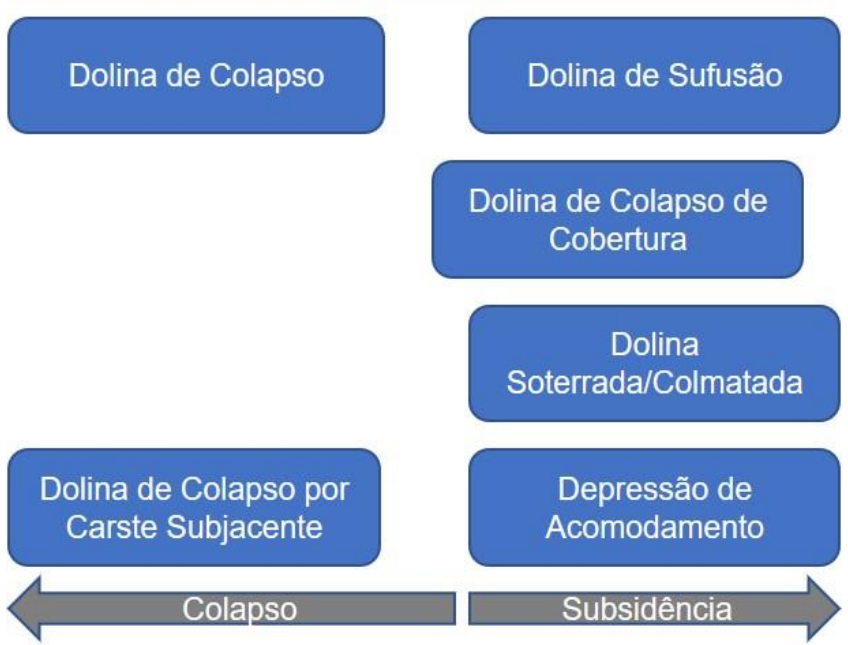

\section{MORFOLOGIA DAS DEPRESSÕES E ANÁLISES MORFOMÉTRICAS/ESPACIAIS}

Apesar das dolinas terem a tendência de possuir formas circulares a semicirculares quando vistas em planta e formatos de funil, bacia ou balde quando vistas em perspectiva, na natureza podem ser encontradas feições dos mais variados formatos e tamanhos, algumas medindo poucos metros de diâmetro ou profundidade, outras contabilizando medidas superiores a várias centenas de metros. $A$ forma e tamanho das depressões observadas em superfície é função dos processos de gênese e evolução. Conforme Kranjc (2013), alguns autores classificam dolinas em função da sua origem, outros em função da forma. Por este motivo a terminologia eslovena para dolinas envolve 14 tipos diferentes, sendo que outras tentativas de classificação alcançam dezenas de tipologias adicionais. Quanto mais elementos são postos em análise, como estágio de evolução, tipo de sedimentos de recobrimento e fatores climáticos, mais tipologias ou subtipologias de dolinas podem ser criadas.

Segundo Sauro (2012), apesar do processo de dissolução ser o mais importante na formação de uma dolina, outros processos operam em conjunto no sentido de modelar a depressão, tais como o intemperismo e formação de solo, a captura de sedimentos, o escoamento superficial, processos de encosta e de evacuação dos materiais acumulados em seu interior. Apesar dos formatos tridimensionais mais comuns se apresentarem entre tigela/bacia (aproximadamente hemisférico), funil (aproximadamente cônico) e de poços (aproximadamente cilíndrico), ocorrem feições truncadas, de fundo chato, estrelares ou irregulares e de contornos acentuados, como aquelas desenvolvidas em rocha exposta. As tipologias morfológicas mais essenciais geralmente são associadas a processos de gênese e evolução: tigela/bacia e funil por dissolução e subsidência lenta de materiais (sufusão); poços/balde de formato cilíndrico por colapsos de rocha ou solo; estrelares, poligonal ou cockpit remodeladas por canais superficiais de escoamento; e irregulares de feições acentuadas por dissolução em rocha nua.

São observadas algumas classificações de dolinas baseadas puramente no aspecto morfológico, seja em planta ou seção. Angel et al. (2004) identificaram três tipos principais quando observadas em planta, dividindo-se entre simples, complexa (com uma sub dolina mais profunda) e composta (dolinas coalescidas) que podem ou não conter água em seu interior. O esquema adaptado por Kholer (1995) a partir do desenho apresentado originalmente por Nicod (1972, apud KHOLERr, 1995) se sustenta basicamente na configuração morfológica em secção (Figura 6). 
Figura 6 - Tipologia morfológica de dolinas apresentada por Kholer (1995), adaptada de Nicod (1972) e classificação morfológica de Angel et al. (2004) em planta.
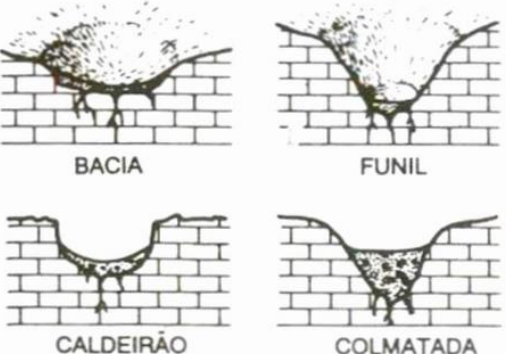

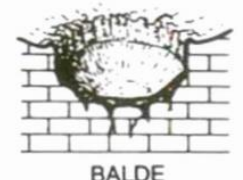

BALDE

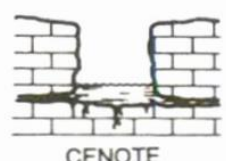

CENOTE

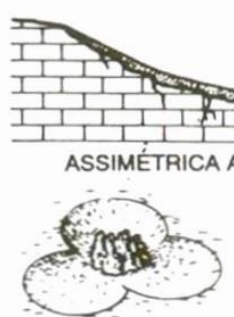

UNALA

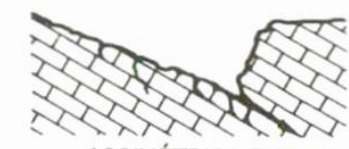
ASSIMÉTRICA FLUVIAL

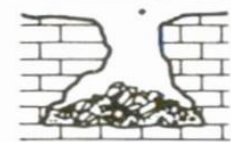

DOLINAS DE ABATIMENTO

Nicod (1972)

\section{Angel et al. (2004)}

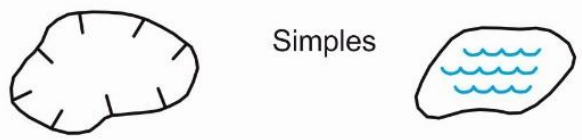

Complexa
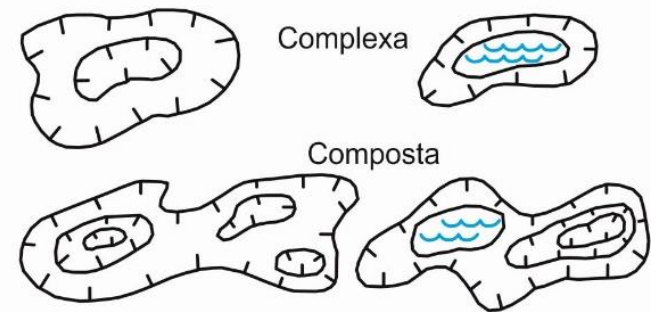

Alguns tipos de dolinas com formatos de poços cilíndricos apresentam água em seu interior são chamadas de cenotes e têm seus melhores exemplares na Península de Yucatán, no México. Sauro (2012) descreve sua formação como por colapsos de sistemas de cavernas submersas que sofrem variações do nível do aquífero em associação à eficiente dissolução por mistura de águas salobras (marinhas). Entretanto, essa tipologia de formato também é empregada para descrever dolinas circulares de bordas escarpadas em rocha com lagos internos, usualmente correspondente ao nível do aquífero (PALMER, 2007), que ocorrem mesmo em regiões interiores.

Em zonas tropicais úmidas, onde o excesso de pluviosidade leva ao escoamento superficial, uma vez que a permeabilidade subterrânea não consegue dar vazão ao grande aporte de água, ocorre a instalação de canais superficiais efêmeros que obliteram os formatos dissolutivos iniciais, geralmente circulares. Estes canais centrípetos dão formas estrelares as dolinas, sendo chamados originalmente de "cockpits" na Jamaica. Este tipo de feição pode ocorrer disseminadamente na paisagem dando forma ao carste poligonal, já descrito anteriormente. Karmann e Ferrari (2002) descrevem uma das mais importantes áreas de carste poligonal do Brasil, na região do Parque Estadual Turístico do Alto Ribeira- PETAR/SP, onde depressões com amplitudes altimétricas de até 300 metros se contrastam com outras das demais áreas cársticas do país.

Em áreas de rocha densamente fraturadas tendem a ocorrer mais dolinas e de tamanhos menores que em maciços menos fraturados, onde ocorrem feiões maiores e com menor frequência (WILLIAMS, 2004). A distribuição de dolinas, portanto, é altamente dependente da estrutura geológica. Sauro (2012) cita que dolinas podem ocorrer individualmente ou em populações de tamanhos variados, com até $200 / \mathrm{km}^{2}$. A inclinação da superfície condiciona a maior ou menor densidade de ocorrências, sendo que em superfícies inclinadas a possiblidade é menor que em superfícies planares. Ele argumenta que dois tipos principais de planaltos cársticos ocorrem em função da distribuição de dolinas, o individual (mais comum) e o chamado sistema favo de mel (honeycomb), havendo, entretanto, situações intermediárias entre os tipos. Também existe forte relação entre a ocorrência e alinhamentos de dolinas com as estruturas do pacote rochoso como linhas de falha, ou a intersecção entre duas ou mais fraturas, condicionando muitas vezes o centro da depressão. Para Ford e Williams (2007) a questão da distribuição difere entre densidade de feições por área $\left(\mathrm{n} / \mathrm{km}^{2}\right)$ e sua organização espacial (isoladas, agrupadas, uniformemente distribuídas e randômicas na área). Quando ocorrem de forma contínua e justapostas na superfície cárstica, como no carste poligonal, o padrão é chamado de "caixa de ovos" pelos autores.

Análises morfométricas e de distribuição de dolinas são ferramentas utilizadas há bastante tempo para interpretações evolutivas do carste, comparações entre regiões diferentes sem fatores subjetivos e para subsidiar análises ambientais ligadas ao complexo sistema hidrológico. Conforme 
Ford e Williams (2007), o grande valor de análises morfométricas minuciosas no carste é que ressaltam, através de dados quantitativos, aspectos inesperados e propiciam novas hipóteses. Trabalhos detalhados sobre o tema são desenvolvidos há bastante tempo, destacando-se estudos como o de Williams (1972) que identificou padrões morfológicos antes considerados caóticos no carste de Nova Guiné; Day (1976) que estudou depressões pouco profundas no carste tropical da Jamaica e realizou analogias com feições similares em clima temperado; Bondesan et al. (1992) que sumarizaram os vários parâmetros utilizáveis para análises morfométricas de dolinas e discutiram a questão do processamento destes dados e a significância de análises estatísticas correlatas ao tema; e Denizman (2003) que identificou uma grande quantidade de dolinas em uma área igualmente extensa na Flórida e foi um dos primeiros trabalhos realizados com o auxílio sistemas de informação geográfica (SIG), que acelerou as análises e reduziu potenciais erros humanos.

\section{CONSIDERAÇÕES FINAIS}

Desde Cvijić, no final do século XIX, inúmeras denominações foram sendo criadas e atribuídas a tipologias específicas do carste, numa tentativa de encontrar padrões relacionáveis a este complexo sistema. A dificuldade de classificação de paisagens cársticas de evolução complexa, com influência de inúmeros fatores externos e a impossibilidade de uma tipologia genética universal favoreceu a adoção no Brasil de classificações mais descritivas, entre feições superficiais (exo) e subterrâneas (endo). Entretanto, algumas abordagens internacionais mais recentes, pós ano 2000, vêm ressaltando especialmente os processos, nem sempre visíveis, que podem ou não resultar em feições típicas, como as dolinas. Tais abordagens destacam os processos espeleogenéticos, muito associados a dinâmica hidrológica e subterrânea do carste. Nesta presente revisão foi possível reunir algumas propostas de classificação do carste e rever mecanismos importantes, responsáveis pela diferenciação entre tais tipos de paisagens. Futuros trabalhos de caracterização regional/local do carste poderiam, assim, qualificar mais detalhadamente as diferenciações encontradas em suas respectivas áreas de estudo.

Por fim, em relação às dolinas, também se observa a dualidade entre classificações genéticas e morfológicas. Entretanto, na natureza ocorrem fatores intervenientes que dificultam a classificação objetiva, por haver uma mistura tanto de formas como processos. As classificações genéticas analisadas mostram certo descompasso de terminologias, utilizadas de formas diferentes por determinados autores. Por este motivo esta revisão buscou realizar uma síntese ajustada das propostas já elaboradas por diversos trabalhos de forma que se possa uniformizar a aplicação da nomenclatura. A distinção entre depressões cársticas apenas pelo formato, apesar de mais objetiva, pode implicar em perdas de informações acerca da evolução ambiental. Neste sentido, em próximos trabalhos pretende-se adotar as tipologias genéticas aqui resumidas em associação com análises morfológicas para melhor caracterização dos ambientes cársticos sob análise.

\section{REFERÊNCIAS}

ANGEL, J. C.; NELSON, D. O.; PANNO, S. V. Comparison of a new GIS-based technique and a manual method for determining sinkhole density: An example from Illinois' sinkhole plain. Journal of Cave and Karst Studies, v. 66, n. 1, p. 9-17, 2004.

AULER, A. S.; KLIMCHOUK, A.; BEZERRA, F. H. R. B.; CAZARIN, C. L.; ENES-SILVA, R.; BALSAMO, F. Origin and evolution of Toca da Boa Vista and Toca da Barriguda cave system in northeastern Brasil. In: KLIMCHOUK, A.; PALMER, A.; WAELE, J. D.; AULER, A. S.; AUDRA, P. (Eds.). Hypogene karst regions and caves of the world. [s.l.] Springer, 2017. p. 827-840. https://doi.org/10.1007/978-3-319-53348-3 56

BAKALOWICZ, M. Epikarst. In: WHITE, W. B.; CULVER, D.C. (Eds.), Encyclopedia of Caves. Second Ed. New York: Elsevier, 2012. pp. 284-288. https://doi.org/10.1016/B978-0-12-3838322.00038-4

BAKALOWICZ, M. Epikarst processes. In SHRODER, J. (EDITOR IN CHIEF), FRUMKIN, A. (Ed.) (Org.). Treatise on Geomorphology. San Diego, CA: Elsevier Inc, 2013, v. 6, p. 164-171. https://doi.org/10.1016/B978-0-12-374739-6.00100-7

BECK, B. Soil piping and sinkholes failures. In: WHITE, W. B.; CULVER, D.C. (Eds.), Encyclopedia of Caves. Second Ed. New York: Elsevier, 2012. pp.718-723 
BIGARELLA, J. J.; BECKER, R. D.; PASSOS, E. Estrutura e origem das paisagens tropicais e subtropicais: Fundamentos geológico-geográficos. 1a. ed. Florianópolis: Editora da UFSC, 1994. 425 p. v. 1.

BÖGLI, A. Karst hydrology and physical speleology. Berlin: Springer, 1980. 284p. https://doi.org/10.1007/978-3-642-67669-7

BONDESAN, A.; MENEGHEL, M.; SAURO, U. Morphometric analysis of dolines. International Journal of Speleology, v. 21, p. 1-55, 1992. https://doi.org/10.5038/1827-806X.21.1.1

CAHALAN, M. D.; MILEWSKI, A. M. Sinkhole formation mechanisms and geostatistical-based prediction analysis in a mantled karst terrain. Catena, v. 165, p. 333-344, 2018. https://doi.org/10.1016/j.catena.2018.02.010

ĆALIĆ, J. Karstic uvala revisited: Toward a redefinition of the term. Geomorphology, v. 134, p. 3242, 2011. https://doi.org/10.1016/.geomorph.2011.06.029

CARAMANNA, G; CIOTOLI, G; NISIO, S. A review of natural sinkhole phenomena in Italian plain areas. Nat Hazards, v. 45, n. 2, p. 145-172, 2008. https://doi.org/10.1007/s11069-007-9165-7

COOPER, A. H.; FARRANT, A. R.; PRICE, S. J. The use of karst geomorphology for planning, hazard avoidance and development in Great Britain. Geomorphology, v. 134, n. 1-2, p. 118-131, 2011. https://doi.org/10.1016/i.geomorph.2011.06.004

DAY, M. The morphology and hydrology of some Jamaican karst depressions. Earth Surface Processes, v. 1, p. 111-129, 1976. https://doi.org/10.1002/esp.3290010203

DELLE ROSE, M; FEDERICO, A; PARISE, M. Sinkhole genesis and evolution in Apulia, and their interrelations with the anthropogenic environment. Natural Hazards and Earth System Sciences, v. 4, p. 747-755, 2004. https://doi.org/10.5194/nhess-4-747-2004

DEL PRETE, S.; IOVINE, G.; PARISE, M.; SANTO, A. Origin and distribution of different types of sinkholes in the plain areas of Southern Italy Sossio. Geodinamica Acta, v. 23, n. 1-3, p. 113-127, 2010. https://doi.org/10.3166/ga.23.113-127

DENIZMAN, C. Morphometric and spatial distribution parameters of karstic depressions, lower Suwanee River basin, Florida. Journal of cave and karst studies, v. 65, n. 1, p. 29-35, 2003.

FORD, D. Karst. In: Gunn, J. (Ed.) Encyclopedia of Caves and Karst Science. New York: Fitzroy Dearborn, 2004. p. 1017-1020.

FORD, D. Jovan Cvijić and the founding of karst geomorphology. Environmental Geology, v. 51, p. 675-684, 2007. https://doi.org/10.1007/s00254-006-0379-x

FORD, D.C.; WILLIAMS, P.W. Karst Geomorphology and Hydrology. London: Unwin Hyman, 1989. 601 pp. https://doi.org/10.1007/978-94-011-7778-8

FORD, D.; WILLIAMS, P. Karst hydrogeology and geomorphology. Second ed. Chichester: Wiley, 2007. 562p. https://doi.org/10.1002/9781118684986

GILLIESON, D. Caves. Processes, Development, Management. Oxford, England: Blackwell. 1996. 324p. https://doi.org/10.1002/9781444313680

GUTIÉRREZ, F.; GUERRERO, J.; LUCHA, P. A genetic classification of sinkholes illustrated from evaporite paleokarst exposures in Spain. Environmental Geology, v. 53, p. 993-1006, 2008. https://doi.org/10.1007/s00254-007-0727-5

GUTIÉRREZ, F; PARISE, M; DE WAELE, J; JOURDE, H. A review on natural and human-induced geohazards and impacts in karst. Earth Science Reviews, v. 138, p. 61-88, 2014. DOI: 10.1016/j.earscirev.2014. https://doi.org/10.1016/j.earscirev.2014.08.002

HEIDARI, M.; KHANLARI, G. R.; TALEB BEYDOKHTI, A. R.; Momeni, A. A. The formation of cover collapse sinkholes in North of Hamedan, Iran. Geomorphology, v. 132, n. 3-4, p. 76-86, 2011. https://doi.org/10.1016/i.geomorph.2011.04.025 
HYATT, J. A.; JACOBS, P. M. Distribution and morphology of sinkholes triggered by flooding following Tropical Storm Alberto at Albany, Georgia, USA. Geomorphology, v. 17, p. 305-316, 1996. https://doi.org/10.1016/0169-555X(96)00014-1

JENNINGS, J.N. Karst Geomorphology. Oxford: Basil Blackwell, 1985. 293p.

JONES, W. K.; WHITE, W. B. Karst. In: WHITE, W. B.; CULVER, D.C. (Eds.), Encyclopedia of Caves. Second Ed. New York: Elsevier, 2012. pp.430-438. https://doi.org/10.1016/B978-0-12383832-2.00061-X

KARMANN, I. Evolução e dinâmica atual do sistema cárstico do alto vale do rio Ribeira de Iguape, sudeste do Estado de São Paulo. Tese (Doutorado em Geoquímica e Geotectônica). Instituto de Geociências, Universidade de São Paulo, São Paulo, 1994. 274p. https://doi.org/10.11606/T.44.1994.tde-22042013-163755

KARMANN I.; FERRARI J. A. Carste e cavernas do Parque Estadual Turístico do Alto Ribeira (PETAR), SP - Sistemas de cavernas com paisagens subterrâneas únicas. In Schobbenhaus, C.; Campos, D.A.; Queiroz, E.T.; Winge, M.; Berbert-Born, M.L.C. (eds.), Sítios geológicos e paleontológicos do Brasil. 1aㅡ. ed., vol. 1. Brasília: DNPM/CPRM - Comissão Brasileira de Sítios Geológicos e Paleobiológicos (SIGEP), 2002 p. 401-413

KLIMCHOUK, A. Karst morphogenesis in the epikarstic zone. Cave and Karst Science, v. 21, n. 2, p. 45-50, 1995.

KLIMCHOUK, A. The typology of gypsum karst according to its geological and geomorphological evolution. International Journal of Speleology, v. 25, n. 3-4, p. 49-60, 1996. https://doi.org/10.5038/1827-806X.25.3.4

KLIMCHOUK, A.B. The formation of epikarst and its role in vadose speleogenesis. In: KLIMCHOUK, A.B.; FORD, D.C.; PALMER, A.N.; DREYBRODT, W. (editors) Speleogenesis: evolution of karst aquifers. Huntsville, Alabama: National Speleological Society, 2000. p. 91-99

KLIMCHOUK, A. The karst paradigm: changes, trends and perspectives. Acta Carsologica, v. 44/3, p. 289-313, 2015. https://doi.org/10.3986/ac.v44i3.2996

KLIMCHOUK, A. B. Advances in understanding hypogene karst. In: STAFFORD, K. W.; VENI, G. (Eds.). Hypogene Karst of Texas. Austin: Texas Speleoloogical Survey, 2018. p. 3-15.

KLIMCHOUK, A. B.; SAURO, U.; LAZZAROTTO, M. "Hidden" shafts at the base of the epikarstic zone: a case study from the Sette Communi plateau, Venetian Pre-Alps, Italy. Cave and Karst Science, v. 23, n. 3, p. 101-107, 1996.

KLIMCHOUK, A.B.; FORD, D.C. Types of karst and evolution of hydrogeologic settings. In: KLIMCHOUK, A.B.; FORD, D.C.; PALMER, A.N.; DREYBRODT, W. (editors) Speleogenesis: evolution of karst aquifers. Huntsville, Alabama: National Speleological Society, 2000. p. 45-53

KOHLER, H. C. Geomorfologia Cárstica. In: GERRA, A. J. T.; CUNHA, S. B. (Org.). Geomorfologia: uma atualização de bases e conceitos. 3ª ed. Rio de Janeiro: Bertrand, 1995. p. 309-334.

KRANJC, A. Classification of closed cepressions in carbonate karst. In: SHRODER, J. (EDITOR IN CHIEF), FRUMKIN, A. (Ed.) (Org.). Treatise on Geomorphology. San Diego, CA: Elsevier Inc, 2013, v. 6, p. 104-111. https://doi.org/10.1016/B978-0-12-374739-6.00125-1

LOLCAMA, J. L.; COHEN, H. A.; TONKIN, M. J. Deep karst conduits, flooding, and sinkholes: lessons for the aggregates industry. Engineering Geology, v.65, p.151-157, 2002. https://doi.org/10.1016/S0013-7952(01)00122-3

MARTINI, J. Silicate karst. In: GUNN, J. (Ed.) Encyclopedia of Caves and Karst Science. New York: Fitzroy Dearborn, 2004. p. 1385-1393

PALMER, A. N. Geomorphic interpretation of karst features. In: LAFLEUR, R.G. Groundwater as a Geomorphic Agent. Boston: Allen \& Unwin, 1984. p.173-209.

PALMER, A.N. Cave Geology. Dayton: Cave Books, 2007. 454 p. 
PILÓ, L. B. Morfologia cárstica e materiais constituintes: dinâmica e evolução da depressão poligonal Macacos-Baú - carste de Lagoa Santa, MG. Tese (Doutorado em Geografia). Universidade de São Paulo, São Paulo. 1998. 268p.

PILÓ, L. B. Geomorfologia Cárstica. Revista Brasileira de Geomorfologia, v. 1, n. 1, p. 88-102, 2000. https://doi.org/10.20502/rbg.v1i1.73

SAURO, U. Closed depressions in karst areas. In: WHITE, W. B.; CULVER, D.C. (Eds.), Encyclopedia of Caves. Second Ed. New York: Elsevier, 2012. p.140-155

SISKA, P. P.; GOOVAERTS, P.; HUNG, I. K. Evaluating susceptibility of karst dolines (sinkholes) for collapse in Sango, Tennessee, USA. Progress in Physical Geography, v. 40, n. 4, p. 579-597, 2016. https://doi.org/10.1177/0309133316638816

VENI, G.; DUCHENE, H.; CRAWFORD, N. C.; GROVES, C. G.; HUPPERT, G. N.; KASTNING, E. $\mathrm{H}_{\text {.; }}$ OLSON, R.; WHEELER, B. J. Living with karst: a fragile foundation. Environmental Awareness Series 4. American Geological Institute, 2001. 64p.

WALTHAM, A. C.; BELL, F.; CULSHAW, M. Sinkholes and Subsidence: Karst and Cavernous Rocks in Engineering and Construction. Chichester: Praxis Publishing, 2005. 382 pp.

WALTHAM, A C; FOOKES, P G. Engineering classification of karst ground conditions. Speleogenesis and Evolution of Karst Aquifers, v. 3, n. 1, p. 2, 2005.

WHITE, E. L.; WHITE, W.B. Breakdown morphology. In: KLIMCHOUK, A.B.; FORD, D.C.; PALMER, A.N.; DREYBRODT, W. (editors) Speleogenesis: evolution of karst aquifers. Huntsville, Alabama: National Speleological Society, 2000. p.427-429.

WHITE, W. B. Geomorphology and hydrology of karst terrains. Oxford: Oxford University Press, 1988. 464p.

WILLIAMS, P.W. Morphometric analysis of polygonal karst in New Guinea. Geological Society of America Bulletin, v. 83, $\quad$ n. 3, p. 761-796, 1972 . https://doi.org/10.1130/00167606(1972)83[761:MAOPKI]2.0.CO;2

WILLIAMS, P. W. The role of the subcutaneous zone in karst hydrology. Journal of Hydrology, v. 61, p. 45-67, 1983. https://doi.org/10.1016/0022-1694(83)90234-2

WILLIAMS, P. Dolines In: GUNN, J. (Ed.) Encyclopedia of Caves and Karst Science. New York: Fitzroy Dearborn, 2004. p. 628-642.

WILLIAMS, P. W. The role of the epikarst in karst and cave hydrogeology: a review. International Journal of Speleology, v. 37, n. 1, p. 1-10, 2008. https://doi.org/10.5038/1827-806X.37.1.1

ZWAHLEN, F. Vulnerability and risk mapping for the protection of carbonate (karst) aquifers: final report (COST action 620). Luxembourg: Office for Official Publications of the European Communities, 2004. 297p.

Recebido em: 27/08/2018

Aceito para publicação em: 23/11/2018 